\title{
Pembuatan dan Pemurnian Etanol Dari Nira Aren dengan Menggunakan Teknik Destilasi Refluks
}

\author{
Beni H. Manialupa, Hanny F. Sangiana*, Verna A. Suotha* \\ aJurusan Fisika, FMIPA, Unsrat, Manado
}

KATA K U N I

Bioetanol, Destilasi, Pohon

Aren (Arenga Pinnata)

\begin{abstract}
A B S T R A K
Telah dilakukan pembuatan dan pemurnian etanol dari nira aren dengan menggunakan teknik destilasi refluks. Etanol didapatkan dari air nira pohon aren yang telah terfermentasi secara alamiah dan didestilasi menggunakan teknik refluks untuk memperoleh kemurnian 70-96\% (v/v). Konsentrasi etanol dalam kaldu yang digunakan dalam pemanasan adalah $30 \%$ dengan volume total $7 \mathrm{~L}$ dalam ketel (boiler). Sebelum separasi dimulai dilakukan pengeringan (drying) pada kolom dan kondensor dengan tujuan untuk memisahkan sisa air yang terdapat didalamnya. Hasil menunjukan bahwa etanol kemurnian $70 \%$, 85\%, 90\%, 95\% dan 96\% diperoleh pada proses pemanasan dengan suhu kolom atas $82,81,79.3,78.3$, dan $78.5^{\circ} \mathrm{C}$.
\end{abstract}

KE YW O R D

Bioethanol, Distillation, Palm Tree (Arenga Pinnata)
A B S T R A C T

Ethanol was been prepared and purified by using a reflux distillation method. Ethanol was obtained from a sap water tapped of the palm tree (arenga pinnata) and then was distilled by a reflux separation technique. The ethanol concentration obtained a range of $70-90 \%(\mathrm{v} / \mathrm{v})$, the concentration of yeasted liquor filled inside boiler was of $30 \%$ with a volume $7 \mathrm{~L}$. Prior to a separation conducted the reflux colomn was dried by flowing a warm air aiming remove a remnant water from the packing materials. The result showed that the ethanol with the concentration of $70 \%, 85 \%, 90 \%, 95 \%$ and $96 \%$ were obtained by setting the column temperature at $82,81,79.3,78.3,78.5^{\circ} \mathrm{C}$.

\section{TERSEDIA ONLINE}

1 Februari 2018

\section{Pendahuluan}

Perkembangan kebutuhan energi yang dinamis ditengah semakin terbatasnya cadangan energi (fosil) merupakan masalah utama yang dihadapi dunia saat ini. Di Indonesia tingkat rata-rata komsumsi minyak naik $6 \%$ per tahun (Suroso, 2005), sedangkan cadangan dan produksi minyak bumi mengalami penurunan sebesar $10 \%$ setiap tahun (Bambang, 2006). Selain krisis energi terdapat juga pertimbangan bahwa penggunaan energi bahan bakar fosil merupakan faktor utama terhadap peningkatan konsentrasi $\mathrm{CO} 2$ di atmosfer yang mengakibatkan terjadinya pemanasan global (Yu dkk, 2003). Lebih dari $73 \%$ produksi dari gas karbon dioksida di bumi adalah merupakan hasil produksi pembakaran bahan bakar fosil (Wildenborg dan Lokhorst, 2005). Berdasarkan hal tersebut perhatian dan persaingan untuk mengganti bahan bakar fosil dengan energi terbarukan yang lebih ramah lingkungan mengalami peningkatan serius. Dengan membatasi penggunaan bahan bakar fosil dapat mengurangi kadar polutan gas rumah kaca $\mathrm{CO} 2$ yang berlebih di udara (Demirbas, 2006).

Menurut (Govindaswamy dan Vane, 2007) bioetanol telah diakui sebagai bahan bakar alternatif dari sumber daya hayati yang lebih ramah lingkungan dan dapat diperbaharui. Bahan yang paling umum digunakan sebagai bahan baku produksi bioetanol adalah jagung, tebu dan gandum (Balat dkk, 2008). Untuk tebu, bit gula serta molase merupakan biomassa yang layak untuk fermentasi dan telah digunakan dalam produksi bioetanol, namun bahan baku ini merupakan produk bernilai tinggi yaitu sebagai sumber bahan makanan.

Berdasarkan penelitian sebelumnya bahwa, bioetanol dapat diturunkan dari gula melalui tahap hidrolisis bahan biomassa (Sangian, 2015). Sedangkan menurut (Dufey, 2006) sekitar 60\% produksi bioetanol 
global berasal dari tebu dan $40 \%$ adalah dari tanaman lain.

Pada penelitian ini, diarahkan untuk membuat dan memurnikan etanol dari air nira pohon aren dengan kemurnian $70-96 \%$. Etanol yang digunakan di dapatkan dari air nira pohon aren yang telah terfermentasi secara alamiah. Sebelum proses separasi dimulai dilakukan pengeringan (drying) pada kolom dan kondensor dengan tujuan untuk memisahkan sisa air yang terdapat didalamnya.

\section{Material dan Metode}

Penelitian dilaksanakan di Laboratorium Instrumentasi dan Energi Terbarukan Jurusan Fisika, FMIPA, Universitas Sam Ratulangi. Penelitian ini berlangsung dari bulan April 2017 sampai Juni 2017.

Adapun alat dan bahan yang digunakan yaitu kolom, kondensor, ketel, Erlen meyer, kompor gas, alat uji konsentrasi, termometer digital LH-666 198, pompa air LH-579 22 (20 V). Untuk etanol diperoleh dari air nira pohon aren yang telah terfermentasi secara alamiah.

Dalam penelitian ini, digunakan peralatan destilasi refluks yang telah dimodifikasi berdasarkan peneletian sebelumnya yaitu dengan penambahan komponen pengering (dryer) seperti yang ditunjukan pada gambar berikut:

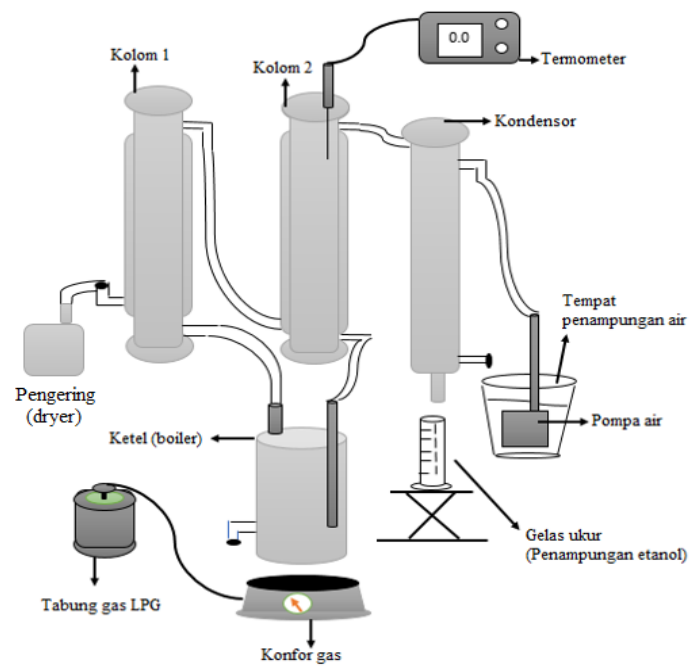

Gambar 1 Desain peralatan destilasi yang telah dimodifikasi berdasarkan penelitian sebelumnya. (Sangian dan Tongkukut, 2011)

\section{Hasil dan Pembahasan}

Dalam proses destilasi, digunakan dua buah kolom refluks dimana di dalamnya terdapat material berupa bahan kemasan (packing material) dan memiliki panjang kolom $200 \mathrm{~cm}$ serta diameter 2 inch. Sebelum proses separasi dimulai, dilakukan pengeringan (drying) pada kolom dan kondensor dengan tujuan untuk memisahkan sisa air yang terdapat di dalamnya. Pada mulanya untuk konsentrasi kaldu yang didestilasi adalah 30\% dengan volume total 7 liter dalam ketel (boiler).
Penelitian dimulai pukul 11.30 wita yaitu pada proses pemanasan kaldu (cap tikus) dengan suhu awal yang terbaca oleh sensor adalah $28.8^{\circ} \mathrm{C}$. Setelah selang waktu 105 menit sejak awal proses separasi, suhu naik menjadi $78.7^{\circ} \mathrm{C}$ dan etanol mulai menetes keluar dari ujung kondensor. Selanjutnya dalam waktu 14 menit, suhu menjadi $82^{\circ} \mathrm{C}$ dan volume etanol pada kolektor (erlen meyer) menjadi $100 \mathrm{ml}$, kemudian itu diukur tingkat kemurniannya dengan menggunakan alat uji konsentrasi, sehingga didapatkan etanol dengan kemurnian $60 \%$ sebagai produk awal pada proses destilasi. Pada suhu yang sama, didapatkan etanol dengan kemurnian $70 \%$ dalam waktu 11 menit. Kemurnian etanol yang didapat menyimpang dengan apa yang harus diperoleh, hal tersebut disebabkan oleh suplai panas yang tidak merata.

Setelah beberapa saat proses berlangsung dilakukan pengontrolan pada suplai panas sehingga suhu turun menjadi $81^{\circ} \mathrm{C}, 79.5^{\circ} \mathrm{C}, 79.3^{\circ} \mathrm{C}$ dan $78.9^{\circ} \mathrm{C}$, dengan kemurnian etanol yang didapatkan masingmasing adalah: 85\%, 89\%, 90\% dan 92\%. Selanjutnya konsentrasi etanol terus meningkat sesuai dengan penurunan suhu, hingga mencapai $96 \%$ pada $78.5^{\circ} \mathrm{C}$ dan $78.6^{\circ} \mathrm{C}$. Setelah itu suhu kembali naik hingga volume etanol dalam kaldu (liquor) habis dan mencapai titik didih molekul air, yang mengakibatkan menurunnya konsentrasi etanol.

\section{Kesimpulan}

> Peralatan destilasi refluks yang berisi bahan kemasan (packing material) dalam kolom dapat memisahkan etanol dan air, hingga mencapai kemurnian 70-96\% bioetanol.

> Pemodifikasian pada peralatan destilasi refluks dengan penambahan pengering (dryer) adalah untuk memisahkan sisa air dalam kolom dan kondensor yang dapat mempengaruhi kemurnian dari etanol.

> Pengontrolan pada suplai panas saat proses pemanasan perlu dilakukan untuk menjaga kestabilan suhu yang dapat mempengaruhi kemurnian etanol pada hasil akhir.

$>$ Etanol dengan kemurnian 70\%, 85\%, 90\%, 95\% dan $96 \%$ diperoleh melalui proses pemanasan pada suhu $82,81,79.3,78.3$, dan 78.5 .

\section{Daftar Pustaka}

Balat, M., Balat, H., and Oz C. 2008. Progress in bioethanol processing. Progress in Energy and Combustion Science. 34: 551-573.

Bambang. 2006. Biodiesel Sumber Energi Alternatif Pengganti Solar Yang Terbuat Dari Ekstraksi Minyak Jarak Pagar. Surabaya: Trubus Agrisarana.

Demirbas, A. 2006. Hazardous emissions, global climate change and environmental precautions. Energy Sources. 1:75-84.

Dufey, A. 2006. Biofuels production, trade and sustainable development: emerging issues. Environmental Economics Programme, 
Sustainable Markets Discussion Paper No. 2, International Institute for Environment and Development (IIED), London.

Govindaswamy, S., and Vane, LM. 2007. Kinetics of growth and ethanol production on different carbon substrates using genetically engineered xylose-fermenting yeast. Bioresource Technol: 98. 67-85.

Sangian, H. F and Tongkukut S. 2011. Study of bioethanol preparation from arenga palm sugar. Departement of Physic. University of Sam Ratulangi.

Sangian, H. F., Widjaya, A., Agnesty, S. Y., and Gunawan, S. 2015. Application of Ionic Liquid [DMIM]DMP Pretreatment in the Hydrolysis of
Sugarcane Bagasse for Biofuel Production. Bulletin of Chemical Reaction Engineering \& Catalysis, 10 (1), 70-77.

Suroso. 2005. Kilang Pengolahan BBM Dioptimalkan, Harian Pagi Jawa Pos 11 Maret 2005.

Wildenborg, T and Lokhorst, A. 2005. Introduction on $\mathrm{CO} 2$ geological storage-classification of storage options. Oil Gas Science and Technology- Rev, IFP. 60: 513-515.

Yu, J., Corripio, AB., Harrison, OP., and Copeland, RJ. 2003. Analysis of the sorbent energy transfer system (SETS) for power generation and $\mathrm{CO} 2$ capture. Adv Environ. 7: 335-345 